\title{
Crianças em notícias: uma perspectiva sob a análise do discurso
}

\section{Children in news: a discourse analysis perspective}

\author{
Ismael Gonçalves Alves ${ }^{1}$
}

Artigo

Original

Original

Paper

Palavras-chave:

Infância

Análise do Discurso

Jornais

\section{Resumo}

Este artigo tem o objetivo de analisar o discurso a respeito das crianças consideradas abandonadas veiculados na mídia impressa do sul catarinense num período em que múltiplas representações infantis se proliferavam nos mais diversos veículos de comunicação do país. Analiticamente, buscaremos perceber como estes discursos foram construídos, que poderes os forjaram e quais suas intencionalidades ao criar uma determinada imagem de Infância.

\begin{abstract}
This article aims to analyze the discourse about children considered abandoned presented by the press in southern Santa Catarina state. It was at the time when the multiple children representation multiplied in several means of communication in the country. Analytically, we try to understand how these discourses were constructed, which powers formed them and what their intentions were by creating a certain image of childhood.
\end{abstract}

Key words:

Childhood

Discourse Analysis

Newspapers 


\section{Introdução}

Este artigo parte do princípio que no decorrer de todo o século XX os discursos sobre a infância e suas diversas representações sociais - menor, carente, abandonada e delinquente - adquiriram grande circularidade nas mais diferentes instituições: no Estado, no aparelho jurídico e assistencial, nas famílias, nos consultórios médicos e na mídia. Importa aqui analisar, a partir de uma notícia em especial, como esta discursividade foi construída e, que poderes forjaram estes enunciados, dentro de um corpus analítico específico, que é o jornal impresso.

Como ferramenta analítica utilizaremos a metodologia da Análise do Discurso (AD) que entende a linguagem "como um traço discursivo em uma história, um nó singular em uma rede", ${ }^{1}$ "estratégias de interlocução, em posições sociais ou em conjunturas históricas [...] atravessadas pelos embates subjetivos e sociais". ${ }^{2}$ Partindo dessa constatação, compreendemos que a $\mathrm{AD}$ não está restrita apenas a interpretações linguísticas e suas unidades formais, ou então, a busca por verdades ocultas, aquilo que o texto suprime e que supostamente deveria ser encontrado. Ao contrário disso, entendemos a AD como possibilidades interpretativas, das quais cabe ao analista através, de ferramentas que lhes são próprias "analisar os discursos enquanto efeitos de sentido, produzidos no momento mesmo da interlocução", ${ }^{3}$ processo este, que consiste em tratar interações existentes entre os indivíduos, através da linguagem verbal e não-verbal.

A AD busca perceber os sentidos produzidos pelo sujeito ao elaborar um determinado discurso, suas intencionalidades; desprendendo especial atenção para a forma como é recebido por quem lê ou ouve suas palavras/signos. $\mathrm{O}$ discurso pode ser entendido então como um efeito de sentido entre enunciador e enunciatário, ou seja, ele "nada mais é do que um jogo, de escritura, no primeiro caso, de leitura, no segundo, de troca, no terceiro, e essa troca, essa leitura e essa escritura jamais põem em jogo senão signos". ${ }^{4}$ É através dessa interação entre enunciador e enunciatário, na qual ambos formam imagens de si mesmos e dos outros, é que buscaremos fundamentar nossas análises.

Para construir o processo investigativo, proposto para este trabalho buscaremos tratar dos conceitos fundamentais da $\mathrm{AD}$, dividindo este artigo em três partes. No primeiro momento apresentaremos o corpus documental a ser analisado (o texto). Em seguida trabalharemos alguns conceitos elementares da Análise do Discurso ao mesmo tempo em que realizaremos o procedimento analítico intercalando texto e metodologia da AD. Por último apresentaremos nossas considerações finais.

\section{Texto:}

\section{Menores Pedintes}

Problema dos mais graves e complexos é, sem dúvida, o dos menores abandonados. Diante de sua gravidade e complexidade, chega-se mesmo a conclusão de que extingui-los torna-se praticamente impossivel, ao menos nas contingências atuais. Elevadíssimo e sempre crescente é o numero de menores em nossa cidade, em nosso município, vivendo na mais extrema miséria, padecendo de fome e outras privações, prescindindo de amparo material e moral.

Temos, é bem verdade um SCAN e algumas outras instituições de fundo filantrópico, que procuram na medida do possível e reduzir à proporções menos aflitivas os múltiplos efeitos decorrente do mal. Admirável a grandiosidade do criciumense, que já compreendeu perfeitamente que, diante da impraticabilidade de uma solução definitiva, o melhor que pode-se fazer é procurar minorar o problema. E por isto, não tem limite de sua generosidade.

Mas, é preciso compreender, por outro lado, que os menores desprotegidos não necessitam da proteção material tão somente. É mister, que lhes dê, também, amparo moral; que, além do pão recebam êles bôa também orientação, para que mais sólido lhes apresente o futuro.

'PÊCHEAUX, Michel. Sobre os contextos epistemológicos da análise de discurso. In: Cadernos de Tradução. № 1. Ed. UFGRS: Novembro de 1998. p. 48.

${ }^{2}$ MAINGUENEAU, Dominique. Análise do discurso: novas perspectivas. Campinas: Ed. Unicamp, 1989. p. 11-12.

${ }^{3}$ FISCHER, Rosa Maria Bueno. A análise do discurso: para além das palavras e as coisas. In: Educação Realidade. 20(2). Julho/Dezembro de 1995. p. 22. 
Há, por exemplo, uma causa que muito contribuí para o agravamento da questão que, segundo se tem observado, não vem sendo encarada com necessária seriedade. É o caso dos menores pedintes.

É freqüente sermos assediados por garotos, esmoleres que, com um cinismo à tôda prova, perdoável no entanto por originar-se na natural ingenuidade das crianças, encontram sempre uma história comovente com que tentam persuadir-nos a entregar-lhes nosso trocado. Quase sempre a frase que nos chega aos ouvidos é: "Me dá um trocadinho para comprar um pão!”, ou então, “Por que o papai é entrevado e não pode trabalhar”, ou ainda, "Por que a minha mãe é viúva e não tem o que comer!". Não se duvida absolutamente que a família dêsses sofram privações. Mas, a verdade, que não admite objetivações, é quê a maioria desses pequenos, que vivem a pedinchar de porta em porta, uso o dinheiro adquirido em futilidades, tais como, bombinhas, foguetes, balas e outras mais. Involuntária e impensadamente estamos incentivando-os à malandragem, à preguiça. E o futuro dessas crianças como conseqüencia natural do ambiente que lhes foi propiciado, não poderá ser promissor.

Por esta razão, criciumense, quando um menor lhe pedir um níquel, não the dê. Dêlhe um pedaço de pão, uma xícara de café, ou uma roupa usada. Não colabore para sua desmoralização futura, e não seja cúmplice de sua desgraça no porvir. E quando vir um dêsses pequenos, talvez daqui a dez ou quinze anos, bem educado e bem orientado na vida esteja certo: ali encontrará um amigo, um coração reconhecido por daquilo que você não fez, mas deixou de fazer.

Fonte: LIMA, Ézio. Menores pedintes. In: Tribuna Criciumense, 22 de Junho de 1955.

\section{Sujeito/Enunciador}

Ao examinar a construção do sujeito/ enunciador, a $\mathrm{AD}$ não busca identificação do que este fala sobre si mesmo, mas procura reconhecer sua aparência através de seus atos de fala. O sujeito interpelado pela $\mathrm{AD}$ não é aque- le que supostamente decide sobre as possibilidades de sentido de seu enunciado, operando com total autonomia sobre seus atos de fala; mas aquele que ocupa uma determinada posição social e a partir dela fala, representando-a. Para Michel Foucault, o sujeito se vê como fonte e ponto de partida de seu discurso; ele atua como se tivesse pleno domínio sobre o que enuncia, quando na verdade, ele nada mais é do que o suporte e o efeito destes enunciados encharcados de ideologias que determinam os discursos. ${ }^{5}$ Assim, o autor do texto que será por nós analisado terá sua construção identitária baseada na noção de que como sujeito, ele ocupa uma determinada posição social e a partir dela fala, influenciado por um conjunto ideológico que determinam seus atos de fala.

O poder das palavras é apenas o poder delegado do porta-voz cujas palavras (quer dizer, de maneira indissociável, a matéria de seu discurso e sua maneira de falar) constituem no máximo um testemunho, um testemunho entre outros da garantia de delegação de que ele esta investido. ${ }^{6}$

Por ser oriundo das classes médias da cidade, o autor do texto se coloca em uma posição de superioridade em relação ao suposto "problema" das crianças, atribuindo o abandono destes infantes à falta de moralidade das famílias pobres urbanas. Como membro da burguesia este se apresenta como um dos guardiões da moral, cabendo a ele a outros membros de seu circulo social providenciar esta moralidade perdida. Por isso, ele alerta seus pares sobre o problema, reforçando a idéia de que apenas o amparo material não era suficiente para se construir bons cidadãos: "É mister, que lhes dê, também, amparo moral; que, além do pão recebam êles bôa também orientação, para que mais sólido lhes apresente o futuro".

Seu artigo foi escrito em um momento em que a cidade, assim como o Estado brasileiro, colocavam as crianças na centralidade de seus discursos, pois estas eram percebidas como futuro da nação, embrião sobre o qual se ergueria a grande nação brasileira "problema dos mais graves e complexos é, sem dúvida, o dos menores abandonados". Identificando a condição da criança desamparada como com- 
plexa, ele busca dissuadir seus leitores para importância do caso, convocando-os para participarem dessa cruzada.

Ao colocar também no texto suas experiências pessoais relativas ao suposto problema, "É freqüente sermos assediados por garotos, esmoleres que, com um cinismo à tôda prova" ele tenta legitimar sua posição como enunciador, agindo como alguém que também é interpelado por esta problemática, sendo tocado por ela. Sobre o lugar e a cena Dominique Maingueneau afirma, "ela submete o enunciador a suas regras, ela igualmente o legitima, atribuindo-lhe a autoridade vinculada institucionalmente a este lugar". Essa relação entre enunciador e suas experiências pessoais, "Quase sempre a frase que nos chega aos ouvidos é" "encontram sempre uma história comovente com que tentam persuadir-nos a entregar-lhes nosso trocado", tratam de dar legitimidade ao texto, localizando-o no tempo e no espaço. Segundo Michel Foucault, isso se dá devido à forte pressão do enunciatário/leitor para a existência de um autor o que daria uma suposta condição de veracidade e identidade ao texto.

[...] eis que, agora, se lhes pergunta, quem o escreveu; pede-se que o autor preste contas da unidade do texto posta em seu nome; pede-se-lhe que revele, ou ao menos sustente, o sentido oculto que os atravessa; pede-se-lhe que os articule com sua vida e suas experiências vividas, com a história real que os viu nascer. ${ }^{8}$

Esta relação encontrada no texto entre experiências vividas pelo autor e a cena enunciativa, leva-nos para a próxima tarefa analítica, que é a de nos aproximar dos enunciatários, desvelando a quem o texto se destina tentando perceber ainda os efeitos de sentido que o enunciador buscou produzir sobre seus enunciatários.

\section{Enunciatário/Destinatário}

Apesar de ser um discurso dirigido à sociedade como um todo, sem um destinatário explícito, a veiculação de um texto sobre a si- tuação dos menores na cidade de Criciúma em um jornal de considerável rotatividade, tem a específica intenção de alcançar sujeitos pertencentes às classes médias (destinatário implícito), já que nesse período o referido meio de comunicação por seu valor monetário, não se destinava às camadas populares, agravado ainda pelo fato de boa parte da população de a cidade não ser letrada.

Por serem detentores dos meios de produção e financiadores de instituições filantrópicas "que procuram na medida do possivel e reduzir à proporções menos aflitivas”, o autor busca apresentar-lhes uma situação que não era nova, mas que se agravava a cada dia "Elevadíssimo e sempre crescente é o numero de menores em nossa cidade", cabendo a eles tomarem posições mais enérgicas a fim de minorar a situação, pois a mesma "não vem sendo encarada com necessária seriedade". Essa construção textual empreendida pelo enunciador, buscava comprometer seus leitores com a situação da criança desamparada transformando-os, em cúmplices ou heróis de uma "cruzada" pró-infância.

\section{Sobre O Texto/Discurso}

O texto por nós apresentado está relacionado à intensa veiculação nos jornais locais para a problemática da infância desamparada, no momento em que o município passava por um acelerado processo de industrialização impulsionado pela indústria carvoeira, trazendo consigo um número considerável de novos moradores sem experiências urbanas. Diferente do que ocorria com as classes médias em que a família nuclear burguesa era o sustentáculo de suas relações sociais, as camadas pobres urbanas não engendraram da mesma forma a norma familiar, onde a criança era o principal objetivo da união conjugal. Para Michel Foucault, desde o final do século XVIII a criança e a infância aparecem como principal finalidade de governo, não bastava apenas gerar filhos, era preciso fomentar sua vida através de condições econômicas que ga- 
rantissem sua sobrevivência e, nesta empreitada, a família aparece como principal guardiã destes pequenos sujeitos. ${ }^{9}$

Desta forma, podemos compreender que esses discursos sobre a infância, produziram as condições necessárias para a emergência de uma discursividade sobre a criança pobre, ou seja, aquela que estava em desacordo com os padrões burgueses da criança universal, cercada de carinho e cuidados, herdeira de um futuro promissor "E o futuro dessas crianças", "não poderá ser promissor". Segundo Dominique Maingueneau, através das condições de produção é possível perceber por que em determinado período um discurso adquiriu maior circularidade que outro, provocando até mesmo sua anulação ou invalidação de seus concorrentes.

Através dela [condições de produção], designa-se, geralmente o "contexto social" que "envolve" um corpus, isto é, um conjunto desconexo de fatores entre os quais são selecionados previamente elementos que permitem descrever "uma conjuntura". ${ }^{10}$

Ao ampliarmos o foco de nossas análises ao percebermos que o momento de enunciação do texto corresponde ao período que os temas relativos à infância povoavam os semanários locais, a fim de chamar a atenção das autoridades locais e da população em geral sobre o tema "Admirável a grandiosidade do criciumense, que já compreendeu perfeitamente”. A partir de algumas passagens do texto, "é frequente sermos assediados", "tentam persuadir-nos", "nos chega aos ouvidos", "múltiplos efeitos decorrente do mal"; é possível deduzirmos que até o momento da enunciação do referido discurso, o enunciatário não tenha se envolvido de forma consistente com o tema; apenas quando o "problema" chega até ele, deixando de ser um evento restrito das periferias, é que ele se torna alvo do seu discurso.

Outra característica do documento analisado diz respeito à sua tipologia. Através dela é possível capturar os objetivos específicos da interação entre linguagem e condição de produção. Para Eni Orlandi é possível estabelecer uma tipologia através da relação entre enunciador e enunciatário, "onde o locutor leva em conta seu interlocutor de acordo com uma certa perspectiva" onde a reversibilidade ou a troca de papéis determina a dinâmica da interlocução, derivando daí a polissemia, ou seja, maior ou menor relação dos interlocutores com o objeto do discurso. ${ }^{11}$ A partir desta constatação é possível caracterizar esse texto como polêmico, pois ele permite uma certa reversibilidade entre os interlocutores. Ao conclamar os habitantes da cidade a se envolverem com a questão da criança abandonada, ele tenta dissuadir a população, através da opção "escolha de lados" a ocupar um papel de centralidade na questão do "menor", ao mesmo tempo em que ele atribui a ela responsabilidade por tal situação "Involuntária e impensadamente estamos incentivando-os", ele afirma que ao tomar uma posição consciente o cidadão seria retribuído por sua boa ação "daqui a dez ou quinze anos, bem educado”, "ali encontrará um amigo, um coração reconhecido por daquilo que você não fez, mas deixou de fazer".

Percebe-se ainda por diversas passagens do texto a presença de uma interdiscursividade, onde o texto é perpassado por outros discursos. Para Freda Indursky, o interdiscurso opera sobre os enunciados transformando seus elementos permitindo a incorporação elementos exteriores, princípios constitutivos que interferem em seu sentido ligando-o a uma noção de heterogeneidade. ${ }^{12}$ Encontram-se presentes no texto um forte apelo à moral do trabalho "uso o dinheiro adquirido em futilidades", "impensadamente estamos incentivando-os à malandragem, à preguiça”, no qual o menino desde pequeno deveria ser encaminhado ao mundo do labor, pois esperava-se que no futuro ele fosse capaz de manter e sustentar uma família, moral e economicamente. Além disso, ao se referir às crianças, o enunciador as entende como não sujeitos, incapazes de produzir sua própria história, cabendo aos adultos zelarem por seu desenvolvimento psicossomático "originar-se na natural ingenuidade das crianças", "bem orientado na vida". Imbuído sobre os preceitos da medicina higie- 
nista que tratava não só do corpo físico, mas expandia sua atuação para o campo da moral, "os múltiplos efeitos decorrentes do mal", o autor chama atenção para a incapacidade de essas crianças se transformarem em futuros cidadãos responsáveis pelo engrandecimento da pátria brasileira "desmoralização futura", "cúmplice de sua desgraça no porvir". Observamos, ainda, como uma das principais características do texto a contradição, pois ao mesmo tempo em que ele conclama a sociedade para minorar a situação de miséria das crianças/menores "Por esta razão, criciumense, quando um menor lhe pedir um níquel, não lhe dê", ele também afirma que "extingui-los torna-se praticamente impossivel".

Com base nos elementos acima analisados podemos perceber a tentativa de se construir uma discursividade homogeneizante sobre a criança pobre, que eram apresentadas como depauperadas e portadoras da incivilidade, dignas da compaixão de homens e mulheres longânimes capazes de resgatá-las da barbárie. Esse discurso midiático tratou de construir e fortalecer estereótipos sobre a infância negligenciada pelo Estado e pela sociedade, oferecendo soluções simplistas e discriminatórias para a solução do "problema", sem com isso questionar o real papel da coletividade na minoração da condição de pobreza que envolvia a população infantil da cidade.

\section{Considerações Finais}

Esta aventura analítica teve a intenção de compreender os discursos de uma determinada classe social historicamente privilegiada sobre outra menos favorecida. Tendo sempre a seu lado poderosos aparelhos ideológicos, como a mídia impressa que "[...] selecionam, ordenam, estruturam e narram, de uma determinada forma, aquilo que elegem como fato digno de chegar até o público", ${ }^{13}$ esta classe privilegiada disseminou práticas e valores produzidos por ela mesma, sem dar espaço para que discursos divergentes fossem apresentados.

\section{Referências}

1. BOURDIEU, Pierre. A economia das trocas linguísticas: o que falar quer dizer. São Paulo: Edusp, 1999.

2. DE LUCA, Tania Regina; MARTINS, Ana Luiza. Imprensa e cidade. São Paulo: Ed. UNESP, 2006.

3. FISCHER, Rosa Maria Bueno. A análise do discurso: para além das palavras e as coisas. In: Educação Realidade. 20(2). Julho/Dezembro de 1995.

4. FOUCAULT, Michel. A ordem do discurso. $11^{\mathrm{a}}$ edição. São Paulo: Ed. Loyola, 1996.

5. FOUCAULT, Michel. A ordem do discurso. $11^{\mathrm{a}}$ edição. São Paulo: Ed. Loyola, 1996.

6. FOUCAULT, Michel. Microfísica do poder. 15.ed. Rio de Janeiro: Graal, 2000.

7. INDURSKY, Freda. A fala dos quartéis e as outras vozes. Campinas: Edcampi, 1997.

8. MAInGUEnEAU, Dominique. Análise do discurso: novas perspectivas. Campinas: Ed. Unicamp, 1989.

9. ORLANDI, Eni Pulcinelli. A linguagem e seu funcionamento: as formas do discurso. São Paulo: Ed. Brasiliense, 1999.

10. PÊCHEAUX, Michel. Sobre os contextos epistemológicos da análise de discurso. In: Cadernos de Tradução. $\mathrm{N}^{0}$ 1. Ed. UFGRS: Novembro de 1998.

\section{Endereço para Correspondência:}

Ismael Gonçalves Alves

ismaelmaya1@yahoo.com.br

Rua General Carneiro, $n^{\circ} 460$

sala 716 - $7^{\circ}$ andar - Ed. Dom Pedro I

Centro - Curitiba - PR

CEP: $800.060-150$ 